\title{
Strategies for innovative teaching and learning Part 3: Connecting with students from a distance
}

\author{
Diana Bantz, Cynthia M. Thomas, Constance E. Mclntosh \\ School of Nursing, Ball State University, USA
}

Received: April 6, 2021

DOI: $10.5430 /$ jnep.v11n10p19
Accepted: May 27, 2021

Online Published: June 10, 2021

URL: https://doi.org/10.5430/jnep.v11n10p19

\begin{abstract}
The third article in a three-part series discusses ways to enhance communication with students and promote connectedness when delivering a distance online course. Students in distance programs may have feelings of not being connected to the instructor and peers leading to dissatisfaction and isolation. Methods of how the instructor can promote an environment of connectedness through the use of announcements, video conferencing, video updates, scheduled phone calls, and office hours will be discussed. The first paper discussed the history of distance learning, the positives and negatives of online learning, advantages and disadvantages of online learning, and the initial considerations for establishing online courses. The second paper delved into understanding of the learning platform, developing a course model, creating individual assignment rubrics for courses, requiring active participation from both instructor and students, and setting-up quality communication.
\end{abstract}

Key Words: Online instruction, Connectedness, Innovative teaching, Teaching strategies, Online learning, Distance education

\section{INTRODUCTION}

Distance education provides a different experience than the traditional on campus experience. A positive of distance education is the opportunity for students to pursue educational goals without requiring on campus attendance. A negative is students without in person classes may have feelings of not being connected to the university, faculty, and other students. Part-one of the three-part series provided a brief overview of the history of distance learning, positives and negatives of online learning, advantages and disadvantages of online learning, and initial considerations for establishing online courses. Part-two of the series discussed how to deliver a distance education online course by understanding how to use the learning platform, developing a course model, creating individual assignment rubrics for courses, requiring active participation from both instructor and students, and settingup quality communication. This third article continues the discussion of how to deliver a distance education online course that provides an environment that promotes connectedness. Different methods of connecting and communicating using announcements, video conferencing, video updates, scheduled phone calls, and office hours are discussed.

*Correspondence: Cynthia M. Thomas; Email: cmthomas@bsu.edu; Address: School of Nursing, Ball State University, USA. 


\section{Strategies for Innovative Teaching and Learning}

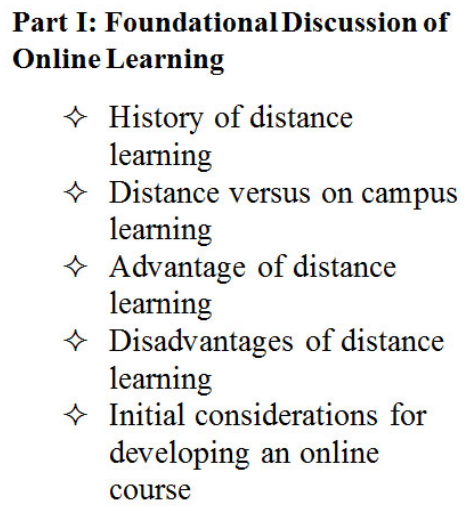

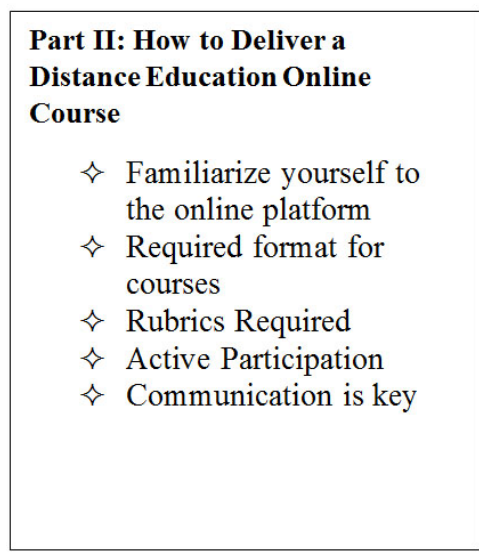

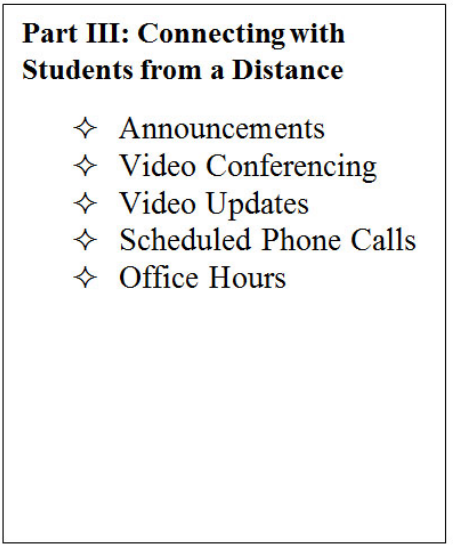

Figure 1. Strategies for Innovative Teaching and Learning outline

Online learning has expanded educational opportunities for students and has been a strategy of higher education to increase enrollment. ${ }^{[1]}$ A common theme found in the literature is the importance of creating an online environment that contributes to feelings of connectedness. ${ }^{[2-4]}$ Connectedness is valued by students and contributes to their success and satisfaction with the learning environment. ${ }^{[2,5]}$

Students in distance education often report feelings of being disconnected from the instructor and class. Willging and Johnson found anecdotal information suggesting that online course dropout rate may be twice as high as those attending on-campus classes. ${ }^{[6]}$ One reason cited for students dropping out of an online course was the lack of interaction with the instructor and students in the class. An environment that promotes student connectedness is an important aspect in online learning environments because it may potentially affect learners' levels of motivation and satisfaction. ${ }^{[2,3]}$

Instructor presence has been identified as an important contributor to the online student's perception of being connected. ${ }^{[7,8]}$ Frequent feedback from faculty along with the use of technology increases engagement with instructors and improves class performance. ${ }^{[1]}$ Multiple instructional strategies can be employed to promote instructor presence including the use of announcements, video lectures/updates and individual student assignment feedback, virtual conferencing, email, and virtual office hours. ${ }^{[5,9-11]}$ Depending on the course and student population some strategies will be more effective than others. For example, a course composed primarily of adult learners who work full time may have different needs than a class of traditional undergraduate stu- dents. Adult learners may prefer email communication over virtual or phone meetings whereas the traditional undergraduate student may prefer virtual meetings and video updates. The instructor should carefully consider the expected outcomes for the course and consider strategies that will enhance opportunities for interaction and connectedness. ${ }^{[5]}$ It is important that faculty teaching online courses be proactive in connecting with distant students by careful consideration of instructional strategies (see Figure 2).

\section{ANNOUNCEMENTS}

Announcements are an important strategy to engage with online students. ${ }^{[4]}$ Announcements should be in an area available for communication with students no matter what type of learning platform is being used to deliver the online course. As discussed in article two of the series it is recommended that button placement for navigating the course be placed in a standard format for all courses such as on the left side of the screen. ${ }^{[12]}$ Students should be encouraged to check the announcements on a daily basis thereby receiving important course information, changes, or updates in a timely manner. It makes sense that the placement at the top of the announcement button be close to the top of the learning platform, making it visible and easily accessible to students.

The announcement area provides a consistent place in the online class where the faculty can communicate important information with the entire class. Faculty can use the announcements area to introduce the course, provide an overview for the upcoming week, remind students when assignments are due, provide answers to students' questions that the entire 
class might have similar questions about, provide clarification, and keep student appraised of any updates. Information placed on the announcement page may also be saved for the entire semester and used as verification for specific content. Clear, concise feedback and expectations contribute to student satisfaction with both the course and instructor. ${ }^{[5,13]}$

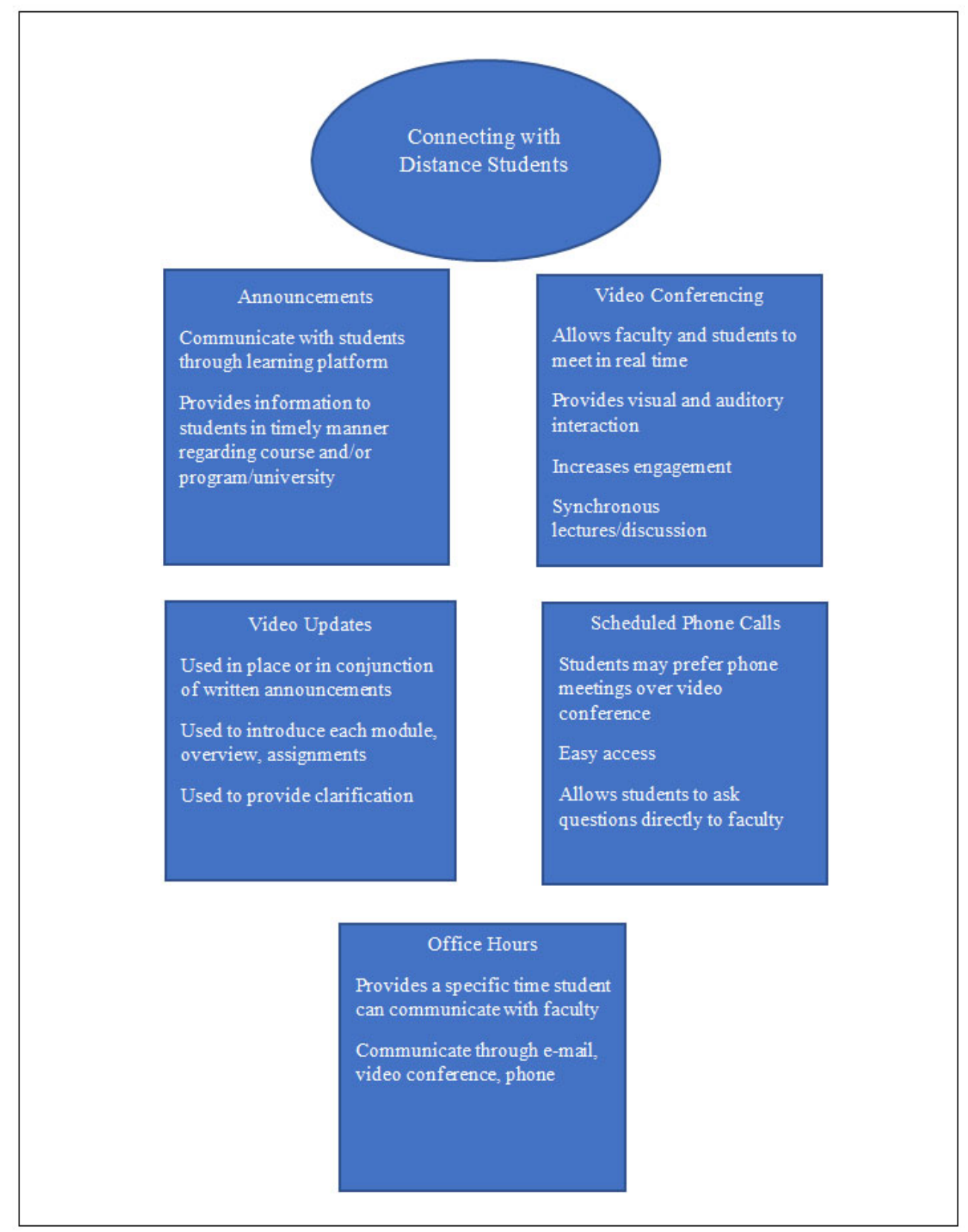

Figure 2. Connecting with Distance Students

Announcements should include clear instruction, due dates, and who to contact if there are any questions (see Table 1). Announcements are an effective way to remind students of information that has been provided earlier. Follow up announcements of important information may increase student participation and satisfaction (see Table 2). Announcements are also a way to communicate information that may be of benefit to the student such as available help from tutoring services, counseling services, and other services.

In addition to providing course information to students, announcements can augment information from the program and/or university traditionally sent by e-mail. Reminders for course registration, health compliance requirements, clinical agency requirements, graduation information, and other important information can be a meaningful use of announcement (see Table 3). 
Table 1. Announcement: Scheduling clinical competency

\begin{tabular}{|l|}
\hline Competency 2 Schedule Times \\
Jennifer Lee \\
All Sections \\
Hello, \\
Competency 2 schedule times have been made available in the calendar app. Please sign up for your Competency 2 schedule time by \\
March 15. \\
Below you will find the invitation for the Zoom Q\&A on March 11 at 8 pm. I will record the session and send you the recording \\
information upon request if you are unable to attend or just want to review the information again. Below is my contact information. \\
Please contact me if you have any questions. \\
Have a great week! \\
Dr. Lee \\
jlee@xxx.edu \\
xxx-xxx-xxxx
\end{tabular}

Table 2. Follow up announcement scheduling clinical competency

Competency 2 Schedule Times
Jennifer Lee
All Sections
Hello,
Please finalize your appointments for Competency 2 schedule time by 9:00 pm tonight. I will be sending out Zoom invites tonight
after 9:00 pm. If you would like the recording from the Q\&A session, please send me an email and I will forward you the
information.
I should know my schedule for the Final Competency by the end of this week and will make those appointments available early next
week. Below is my contact information. Please contact me if you have any questions.
Dr. Lee
jlee@xxx.edu
xxx-xxx-xxxx

Table 3. Examples of announcements with program information

\begin{tabular}{|c|c|}
\hline $\begin{array}{l}\text { Registration } \\
\text { John Smith } \\
\text { Hello, } \\
\text { Each student with a Summer } 2021 \text { course on their plan of study } \\
\text { should have received an email from me by now with your course } \\
\text { registration number and the steps to take to register. If you did } \\
\text { not receive an email but have a course on your plan, please } \\
\text { contact me immediately via email. } \\
\text { The School of Nursing deadline to be registered for your Spring } \\
2021 \text { Nursing classes is Friday, April 9, } 2021 \text { at 8am EST. } \\
\text { Thank you, } \\
\text { John Smith } \\
\text { School of Nursing } \\
\text { Academic Advisor } \\
\text { jsmith@xxx.edu } \\
\text { xxx-xxx-xxxx }\end{array}$ & $\begin{array}{l}\text { COVID-19 Vaccination } \\
\text { Documentation } \\
\text { Jane Jones } \\
\text { You may now submit your COVID-19 vaccination } \\
\text { documentation to your compliance account under Optional } \\
\text { Requirements. You will have the choice to either enter each dose } \\
\text { or the certification that you are fully vaccinated. Please make } \\
\text { sure your name and date are included on the documentation. } \\
\text { With classes beginning in just a few days, this is your final } \\
\text { chance to submit required items in time to be in compliance. } \\
\text { Please make sure you check your account and that all items } \\
\text { have been submitted AND accepted. } \\
\text { Jane Jones } \\
\text { School of Nursing } \\
\text { Compliance Coordinator } \\
\text { jjones@xxx.edu } \\
\text { xxx-xxx-xxxx }\end{array}$ \\
\hline
\end{tabular}

\section{VIDEO CONFERENCING}

Video conferencing (VC) can be a valuable tool that helps instructors connect and build relationships with students. ${ }^{[10,11]}$ Lack of in person interaction with faculty and other students often is cited by online students as a reason for feelings of isolation and being disconnected from the campus community. ${ }^{[14-16]}$ Video conferencing is a tool that allows faculty and students to meet and see each other in real time. VC can 
be used to enhance students feeling engaged with the class. Synchronous lectures, class discussion, meetings with one student, a small group, or larger groups are just some of the ways to use video conferencing.

Synchronous lectures can be used along with asynchronous lectures to enhance student engagement in the course. The learning outcomes to be achieved along with where and when to add the synchronous lectures must be carefully considered by the instructor. Martin and Bolliger suggested that the instructor should conduct 2-3 synchronous meetings during the semester to enhance a sense of community. ${ }^{[4]}$ The instructor should carefully consider how the synchronous class will be conducted to enhance student satisfaction, such as whether having the video and microphones (aka. mics) for each participant should be on or off. Olson and McCracken report that keeping student mics enabled enhance student participation. ${ }^{[17]}$ For some students who chose online courses/programs having synchronous lecture may be viewed as a negative. Recording the synchronous lecture and making it available to those who have other commitments may increase student satisfaction.

$\mathrm{VC}$ can be used by the instructor for any type of meeting including individual or group meetings. During the $\mathrm{VC}$, faculty have the opportunity to explain the assignments all in a forum that allows for questions lending to an easy exchange of ideas. ${ }^{[4]}$ Offering VC during the first week of class can set a positive tone to the semester. This initial VC can be used for the faculty to introduce themselves while also setting the tone for the class. Explanation of the course, structure, course outcomes, overview of assignments, the syllabus and course calendar can all be reviewed. VC where the instructor provides an explanation of the different aspects of the course provides clarity for students that is not achieved in other formats. ${ }^{[18]}$

\section{VIDEO UPDATES}

Use of video for online lectures and providing individual feedback has been found to increase student satisfaction with online courses. ${ }^{[15,16,19]}$ Videos may seem more personal, can be replayed, and may allow for an emotional connection between student and faculty. Video updates by the instructor provides another strategy to enhance instructor presence and connect with students in an online course. Faculty can video themselves and place these updates in the announcements area of the course. The video updates differ from the standard text announcements in that they provide both a visual and auditory experience for the student. When providing a video update include clear instructions, if an assignment when due, and who to contact if any questions. Video updates may provide the student a sense that the faculty is invested in the course, offer a more positive experience than reading an announcement, and may appear more personal. ${ }^{[9]}$

Another use of the video update is the introduction/overview of each module in the course. Not meant to replace the textbased introduction/overview, the video update provides both a visual and auditory option for the student to access module requirements. Similar to the use of video to present lectures, video updates can be used by the instructor to present an overview and discuss assignments for each module. For some students, the video updates may be a welcome change from text-based instructions as the video may provide a more dynamic interaction between participants. ${ }^{[15,16]}$

\section{SCHEDULED PHONE CALLS VS EMAIL COMMUNICATION}

Video technology, while a valuable tool to connect with distance students, may not always be the best method of communication or even the desired communication form for distance students. Email is frequently used by faculty and students to communicate in both distance and on campus classes. La Barbera found that frequent, focused, personalized e-mails between the instructor and student can provide a sense of connectedness for the distance student. ${ }^{[5]}$ A negative of email communication is that students may not adequately communicate their questions or concerns leading to a less than satisfactory response from the instructor. ${ }^{[20]}$ Instructors may assume students know how to communicate appropriately through email but students who are used to texting may treat email communication in the same manner thus not conveying the message adequately and in a too causal manner. To circumvent miscommunication through email, provide the students at the beginning of the course clear instruction on the appropriate use and how to compose a professional email. Instructions on what is expected when using email for communication including the use of subject line, correctly addressing the receiver, appropriate tenor and content, and correct spelling and grammar should be addressed. Provide students with information on times when emails are typically read, timeframe to typically expect a response (24-48 hours), and if there are times when emails are not read and responded to, such as the weekend and or holidays. ${ }^{[20,21]}$

While email is convenient and generally a satisfactory means of communication, especially as a reminder that an assignment is due or answering student questions, there may be instances when a phone meeting provides more clarity. Phone meetings may not be viewed as an essential or desired form of communication for most online students but provide an alternative to e-mail communication when students have difficulty understanding an assignment and/or have several 
questions about an assignment. ${ }^{[7]}$ Phone meetings provide the opportunity for the student to ask questions directly to the faculty and receive answers/guidance. The phone meeting allows the student to question further if they still do not understand the information being provided. Students value instructors being responsive to their needs and phone meetings may be more of a personal approach and provides a platform to talk questions through better than in an email. ${ }^{[7]}$ A good rule to follow is if the student sends a second e-mail for further clarification about the same topic/assignment it is time to offer a phone meeting.

Faculty should be mindful that many distance students have full time jobs and other obligations so providing times outside the usual academic hours of 8-5 to schedule meetings may be beneficial and lead to increased student satisfaction. Faculty may want to consider ground rules regarding scheduled phone calls to protect their time, especially if the meeting is outside of office or university business hours. Be specific when communicating with the student about times available for a phone meeting outside of normal office hours. If not available on weekends or late evening hours do not provide an open invitation for the student to set the hours for the meeting. Provide specific times available for a meeting and instructions to schedule/confirm. For example, I am available for a phone meeting on Monday May 2 between $6 \mathrm{pm}-8 \mathrm{pm}$ or Tuesday May 3 between $7 \mathrm{pm}-9 \mathrm{pm}$. Please respond by e-mail within 24 hours of your desired meeting time within the provided time frames, include the date, time, and phone number where you can be reached. Providing clear directions to the student on the response will eliminate miscommunication. Having the student provide their phone number avoids the faculty giving their private number to the student. Inform the student that when the faculty calls the identification may say private.

\section{OFFICE HOURS}

A traditional method to provide students access to faculty is office hours. Office hours provide students the opportunity to drop by to meet with faculty and communicate any class concerns. For online students dropping by the faculty's physical office may not be practical or possible. While distance students can communicate with faculty $24 / 7$ by email, an immediate response is not the norm. For a student with a question or concern waiting for up to 48 hours may lead to the student's dissatisfaction with the communication process.
A predictor for online course satisfaction is linked to student opinion of the instructors' communication behaviors. ${ }^{[22]}$

Office hours for distance students provides the ability to communicate with faculty and expect a response in a short amount of time. For online courses, communication during office hours is done generally through email. While convenient for some communication, emails may lack clarity for student questions and may lead to students feeling a lack of connection with the course and instructor. Incorporating the use of web conferencing technology provides a method for the student to connect and meet with the faculty. Being able to see the faculty may help the student feel more connected and satisfied with the communication process. ${ }^{[11]}$ Some students may prefer to call during office hours and have questions addressed. Whatever method is used to communicate with students during office hours the faculty should be available for quick responses. ${ }^{[1]}$

Consider when establishing office hours to have availability on several different days and hours throughout the week. Limiting office hours to one day during the week will create an obstacle to access for students who may have obligations during that time frame.

\section{CONClusion}

While online distance education may not be the best option for all students seeking a higher education degree online distance learning can offer a quality education for those students searching for an alternative opportunity other than a traditional on campus experience. The three-article series discusses strategies for innovative teaching and learning. This third article focused on how to connect with students from a distance. The first article of the series focused on the history of distance learning, the positives and negatives of online learning, advantages and disadvantages of online learning, and the initial considerations for establishing online courses. The second article focused on how to deliver a distance online course by developing a standard course model, developing rubrics, the use of active participation, and communication. This third article provided tips on communicating with students including: announcements, video updates, video conferences, phone meetings, and office hours.

\section{CONFLICTS OF INTEREST DisClosure}

The authors declare that there is no conflict of interest.

\section{REFERENCES}

[1] Online Learning Consortium. Online learning consortium highlights 2016 online learning landscape. Available from: https://onlinelearningconsortium.org/news_item/onl ine-learning-consortium-highlights-2016-online-lea rning-landscape/

[2] Bolliger D, Inan F. Development and validation of the online student connectedness survey. International Review Of Research In Open 
And Distance Learning. 2012; 13(3). https ://doi.org/10.191 73/irrodl.v13i3.1171

[3] Phirangee K, Malec A. Othering in online learning: an examination of social presence, identity, and sense of community. Distance Education. 2017; 38(2): 160-172. https://doi .org/10.1080/0158 7919.2017.1322457

[4] Martin F, Bolliger DU. Engagement matters: Student perceptions on the importance of engagement strategies in the online learning environment. Online Learning. 2018; 22(1): 205-222. https: //doi.org/10.24059/olj.v22i1.1092

[5] LaBarbera R. The relationship between students' perceived sense of connectedness to the instructor and satisfaction in online courses. Quarterly Review Of Distance Education. 2013; 14(4): 209-220.

[6] Willging P, Johnson S. Factors that influence students' decision to drop out of online courses. Online Learning: The Official Journal Of The Online Learning Consortium. 2019; 13(3). https: //doi.org/10.24059/olj.v13i3.1659

[7] Sheridan K, Kelly M. The indicators of instructor presence that are important to students in online courses. Journal Of Online Teaching and Learning. 2010; 6(4).

[8] Phirangee K, Malec A. Othering in online learning: an examination of social presence, identity, and sense of community. Distance Education. 2017 ; 38(2): 160-172. https ://doi.org/10.1080/0158 7919.2017 .1322457

[9] Araujo Z, Otten S, Birischi S. Teacher created videos in a flipped mathematics class: digital curriculum materials or lessons. Mathematics Education. 2017; 49(5): 687-699. https://doi .org/10.1 007/s11858-017-0872-6

[10] Martin F, Parker MA. Use of synchronous virtual classrooms: Why, who, and how? Journal of Online Learning and Teaching. 2014; 10(2): 192-210.

[11] Lowenthal P, Dunlap J, Snelson C. Live synchronous web meeting in asynchronous online course: reconceptualizing virtual office hours. Online Learning: The Official Journal of The Online Learning Consortium. 2017; 21(4). https://doi.org/10.24059/olj.v21i4 .1285

[12] McIntosh CE, Bantz D, Thomas CM. Strategies for innovative teaching and learning part 2: How to deliver a distance education online course. The Journal of Nursing Education and Practice. 2021; 11(9): 39. https://doi.org/10.5430/jnep.v11n9p39
[13] Jamison T, Bolliger D. Student perceptions of connectedness in online graduate business programs, Journal of Education for Business. 2020; 95(5): 275-287. https://doi.org/10.1080/08832323.2 019.1643698

[14] Ray M, Coon J, Al-Jumaili A, et al. Quantitative and qualitative factors associated with social isolation among graduate and professional health science students. American Journal Pharmacology Education. 2019; 83(7): 6983. PMid:31619819 https ://doi .org/10.5688/ ajpe6983

[15] Scagnoli N, Choo J, Tian J. Students' insights on the use of video lectures in online classes. British Journal Of Educational Technology. 2017; 50(1): 399-414. https://doi .org/10.1111/bjet. 12572

[16] Mandernach B. Robertson S, Steele P. Beyond content: the value of instructor-student connections in the online classroom. Journal Of The Scholarship Of Teaching And Learning. 2018; 18(4): 130-150. https://doi.org/10.14434/josotl.v18i4.23430

[17] Olson J, McCracken F. Is it worth the effort? The impact of incorporating synchronous lectures into an online course. Online Learning. 2014; 19(2).

[18] Ramos-Morcillo A, Leal-Costa C, Moral-Garcia J, et al. Experiences of nursing students during the abrupt change from face-to-face e-learning education during the first month of confinement due to covid-19. International Journal of Environmental Research Public Health. 2020; 17(15): 5519. PMid:32751660 https://doi.org/ 10.3390/ijerph17155519

[19] McCarthy J. Evaluating written, audio and video feedback in higher education summative assessment tasks. Issues In Education Research. 2015; 25(2): 153-169.

[20] Kim D, Yoon B, Yoo D, et al. Etiquette for medical students' email communication with faculty members: a single-institution study. BMC Medical Education. 2016; 16(129): 1-11. PMid:27121179 https://doi .org/10.1186/s12909-016-0628-y

[21] Filippone M, Survinski M. The importance of etiquette in school email. American Secondary Education. 2016; 45(1): 22-27.

[22] Cole A. Testing the impact of student preference for face-to-face communication on online course satisfaction, Western Journal of Communication. 2016; 80(5): 619-637. https://doi.org/10.1 $080 / 10570314.2016 .1186824$ 